\title{
Focal therapy for primary and salvage prostate cancer treatment: a narrative review
}

\author{
Andrew T. Tracey ${ }^{1}$, Lucas M. Nogueira ${ }^{1}$, Ricardo G. Alvim ${ }^{1}$, Jonathan A. Coleman ${ }^{1}$, Katie S. Murray ${ }^{2}$ \\ ${ }^{1}$ Urology Service, Department of Surgery, Memorial Sloan Kettering Cancer Center, New York, NY, USA; ${ }^{2}$ Division of Urology, Department of \\ Surgery, University of Missouri, Columbia, MO, USA \\ Contributions: (I) Conception and design: KS Murray; (II) Administrative support: None; (III) Provision of study materials or patients: None; (IV) \\ Collection and assembly of data: All authors; (V) Data analysis and interpretation: All authors; (VI) Manuscript writing: All authors; (VII) Final \\ approval of manuscript: All authors. \\ Correspondence to: Katie S. Murray, DO, MS. Division of Urology, Department of Surgery, University of Missouri, Columbia, MO, USA. \\ Email: murraykat@health.missouri.edu.
}

\begin{abstract}
Despite innovations in surgical technology and advancements in radiation therapy, radical treatments for clinically localized prostate cancer are associated with significant patient morbidity, including both urinary and sexual dysfunction. This has created a vital need for therapies and management strategies that provide an acceptable degree of oncologic efficacy while mitigating these undesirable side effects. Successful developments in screening approaches and advances in prostate imaging have allowed clinicians to identify, localize, and more precisely target early cancers. This has afforded urologists with an important opportunity to develop and employ focal ablation techniques that selectively destroy tumors while preserving the remainder of the gland, thus avoiding detrimental treatment effects to surrounding sensitive structures. A lack of high-level evidence supporting such an approach had previously hindered widespread adoption of focal treatments, but there are now numerous published clinical trials which have sought to establish benchmarks for safety and efficacy. As the clinical evidence supporting a potential role in prostate cancer treatment begins to accumulate, there has been a growing acceptance of focal therapy in the urologic oncology community. In this narrative review article, we describe the techniques, advantages, and side effect profiles of the most commonly utilized focal ablative techniques and analyze published clinical trial data supporting their evolving role in the prostate cancer treatment paradigm.
\end{abstract}

Keywords: Focal therapy; prostate cancer; primary therapy; salvage therapy

Submitted Aug 30, 2020. Accepted for publication Jun 17, 2021.

doi: $10.21037 / \mathrm{tau}-20-1212$

View this article at: https://dx.doi.org/10.21037/tau-20-1212

\section{Introduction}

\section{Background}

It is estimated that 191,930 men were diagnosed with prostate cancer in the United States in 2020, accounting for $10.6 \%$ of all new cancer cases. Of these, roughly $75 \%$ have clinically localized disease at the time of initial diagnosis (1). Prostate cancer is almost universally asymptomatic in patients with localized tumors, and five-year cancerspecific survival approaches $100 \%$ regardless of initial management. With the potential for a long-life expectancy post-treatment, the quality-of-life impact of therapeutic interventions is a key management consideration. Current guidelines recommend clinicians and patients use cancer risk and personal values to choose between the surveillance, radiation, surgery, or whole-gland cryoablation-all accepted modalities for definitive treatment $(2,3)$. These approaches were historically conceived and empirically developed for patients with cancers clinically detected throughout the gland, ostensibly requiring radical treatment. Though effective, these strategies are also associated with frequent unfavorable toxicities that compromise bowel, 


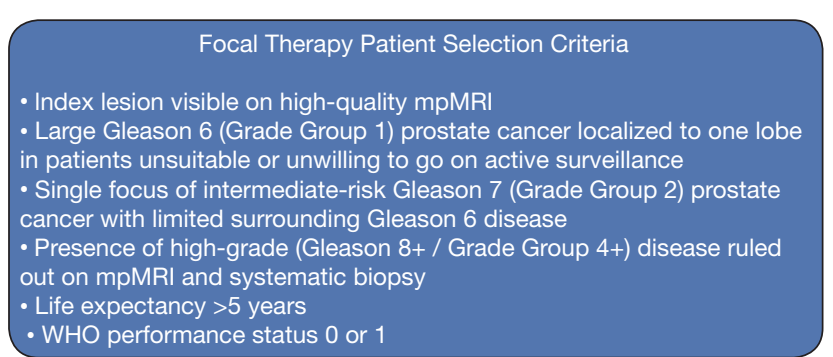

Figure 1 Clinical and pathologic criteria to be considered in the selection of candidate for focal ablative therapies.

bladder and sexual function. Despite evolving guideline recommendations, widespread screening has produced a well-recognized stage migration phenomenon that has helped clinicians to identify early, smaller cancers. Furthermore, the increasing utilization of multi-parametric magnetic resonance imaging (mpMRI) has enhanced screening and increased the opportunity for organ-sparing therapeutic approaches (4). This narrative review describes the existing literature in a rapidly evolving field and provides an overview of the current and future role that this therapy will play in clinically localized prostate cancer. We present the following article in accordance with the Narrative Review reporting checklist (available at https:// dx.doi.org/10.21037/tau-20-1212).

\section{Rationale for focal therapy}

Focal therapies have an established role in the treatment of numerous malignancies, including those of the kidney, breast, and liver. The guiding principle of focal therapy and partial gland ablation is to provide an organ-sparing approach to preserve function while achieving adequate tumor treatment. Ablative techniques for prostate cancer include whole-gland ablation, hemi-ablation of a single lobe of the prostate, and focal ablation- in which a single dominant or index lesion is destroyed using targeted image guidance, such as mpMRI. Studies have shown that up to $86 \%$ of prostates have more than two cancer foci, with over $80 \%$ of patients harboring bilateral disease (5). However, the driving principle behind focal ablation is the concept that the index lesion is the primary driver of disease progression and metastasis, and thus destruction of this lesion can effectively mitigate the risk of spread (6). The combination of MRI-targeted biopsy and standard systematic biopsy further allows for improved detection of cancers, and may reduce the risk of under-staging, aiding with better selection of focal therapy candidates (7).

Data from large published trials, including the Prostate Testing for Cancer Treatment (ProtecT) trial, suggest that radical treatment for low- and intermediate-risk prostate cancer imparts significant morbidity in terms of functional outcomes, while providing questionable survival benefit over active surveillance (8). Over the past two decades, the abundance of evidence supporting the safety of active surveillance protocols in appropriately selected patients has led to a significant increase in utilization. However, despite the increasing acceptance in the urologic community, half of eligible men are not placed on active surveillance due to either patient or physician preference. Furthermore, of those patients who are started on a surveillance protocols, there is a $50 \%$ conversion rate to radical therapy within 10 years (9). Focal ablation has the potential to reduce this pattern of overtreatment by providing a middle ground between radical whole gland treatment and surveillance. Ideally, when appropriately applied to intermediate risk patients, focal therapy can prevent the morbidities of radical therapy and overtreatment while maintaining the safety of surveillance. Stringent patient selection criteria are an essential component of any successful focal ablation program (Figure 1).

\section{Limitations}

Several significant limitations have presented unique challenges to urologists performing focal ablation techniques. Though prostate ablation techniques have been utilized by urologists for treatment of prostate malignancies for over 20 years, a relative dearth of level-one evidence has hampered FDA approval and kept focal ablation out of the guidelines, limiting the application largely to the setting of clinical trials. Critics point to lack of validated post-ablation surveillance and response criteria, which has led to discrepancy in outcomes of published trials. Most experts agree that treatment failure is generally defined as Gleason grade group 2 disease or higher identified on follow-up biopsy. A 2015 consensus panel determined that residual Gleason grade group 1 disease (Gleason $3+3$ ) in the treated area with cancer core length of no more than $3 \mathrm{~mm}$ on a 1-year biopsy does not require retreatment, and thus is considered a treatment success (10). However, the role of a routine systematic biopsy in the posttreatment setting is less well defined in the literature, and there have been notable inconsistencies in published trials. Furthermore, the association of post-procedural prostate-specific antigen 
(PSA) level with treatment outcomes remains largely understudied. Although American Society for Radiation Oncology (ASTRO) and Phoenix criteria for defining PSA recurrence have been applied in focal therapy trials, this approach has not been validated (11). Residual untreated glandular prostate tissue makes PSA level a potentially unreliable indicator of recurrence or treatment failure after any focal treatment. As a result of these and other unresolved issues, the 2017 AUA (American Urological Association)/ASTRO/SUO (Society of Urologic Oncology) guidelines on the treatment of clinically localized prostate cancer instruct clinicians to inform patients that focal therapies for prostate cancer "lack robust evidence of efficacy," and thus patients should be advised that any treatment would be considered experimental and may not be curative (2). The European Association of Urology similarly considers focal therapy to be an investigational modality, recommending against routine implementation outside of clinical trials while awaiting longer term data supporting or refuting oncologic equivalency to established prostate cancer treatments (12).

\section{Methods}

When evaluating the current role of focal therapy for prostate cancer, all relevant publications available from 2000 to 2020 were reviewed using the PubMed database, with a focus on prospective studies and pivotal trials (Table 1). Search terms utilized included "focal ablation," "partial gland ablation," "focal therapy," and "salvage focal therapy." Publications were reviewed for quality and relevance to the subject matter.

\section{Primary focal therapy}

\section{Cryoablation}

Cryotherapy uses freezing techniques to induce cell death by dehydration, resulting in protein denaturation, direct rupture of cell membranes by ice crystals, and vascular stasis with microthrombi. This leads to stagnation of the tumor's microcirculation, and the resulting ischemia leads to cell apoptosis. Cryotherapy of the prostate was originally established as a whole-gland treatment option for clinically localized prostate cancer, but it evolved into a focal application in an attempt to reduce side effects (25). Following transperineal placement of cryo probes, the clinician is able to visualize an ice ball of frozen tumor tissue in real time using transrectal ultrasound guidance. Temperature probes near the target lesion confirm sufficiently low temperatures for adequate cell death, while a urethral warmer and temperature probes near the neurovascular bundles, urethra, and rectum aid the clinician in reducing toxicity to these sensitive structures and reduce risk of sexual, urinary, and gastrointestinal side effects.

Much of the literature supporting the use of focal cryotherapy comes from the Cryo On-Line Database (COLD), which includes a small number of active clinical trials evaluating this approach prospectively (14). Using this database to perform a propensity-matched analysis of 166 patients undergoing focal versus whole gland cryotherapy, Tay et al. found improved sexual function in the focal group, while no difference was seen in biochemical progression-free survival (26). Valerio et al. reported in their systematic review of 11 studies (10 retrospective) a $5.4 \%$ (IQR: $1.1-7.3 \%$ ) risk of significant cancer on posttreatment biopsy, with pad-free continence achieved in $100 \%$ of patients and potency preserved in $81.5 \%$ (IQR: $69.3-88.2 \%$ ) (27). A large number of retrospective studies seem to confirm the relative safety of focal cryotherapy and favorable side effect profile, but further prospective trials in intermediate-risk disease are indicated for this modality.

\section{High-intensity focused ultrasound (HIFU)}

In 2015, HIFU was approved by the FDA for prostatic tissue ablation. HIFU uses sound waves to create thermal energy that destroys target tissue within the prostate. Two commercially available devices have been approved for HIFU application by the United States Food and Drug Administration: Ablatherm (EDAP, Lyon, France) and Sonablate (Sonacare Medical, Charlotte, NC, USA). The ultrasonic waves produced by spherical transducers lead to cell death through two mechanisms: the energy absorbed by the tissue is converted to heat, leading to coagulative necrosis in target tissue; and mechanical destruction of cells is caused by compression and rarefaction cycles, leading to inertial cavitation $(6,28)$.

Unlike treatment with cryotherapy, there is no equivalent of an "ice ball" to allow for real-time visualization of tissue changes. Though magnetic resonance monitoring can be used to assess tumor treatment during HIFU and provides real-time temperature analysis with more accurate detail, the practicality of in-bore treatment makes this a logistical challenge for many urologists (29). 
Table 1 Summary of significant studies evaluating focal ablation of prostate cancer

\begin{tabular}{|c|c|c|c|c|c|c|}
\hline Study & Design & $\begin{array}{l}\text { Ablation } \\
\text { modality }\end{array}$ & Patients & $\begin{array}{l}\text { Grade group } \\
\text { inclusion }\end{array}$ & MRI inclusion & Oncologic outcomes \\
\hline $\begin{array}{l}\text { Shah et al. } \\
(2019)(13)\end{array}$ & $\begin{array}{l}\text { Prospective, } \\
\text { multicenter }\end{array}$ & Cryotherapy & 122 & $90.2 \%$ GG2+ & $\begin{array}{l}\text { MR-visible } \\
\text { lesions only }\end{array}$ & $\begin{array}{l}\text { No residual cancer in } 79.5 \% \text { of patients } \\
\text { treated in index lesion }\end{array}$ \\
\hline $\begin{array}{l}\text { Ward et al. } \\
(2012)(14)\end{array}$ & $\begin{array}{l}\text { Retrospective } \\
\text { multicenter } \\
\text { registry }\end{array}$ & Cryotherapy & 1,160 & $27 \%$ GG2+ & $\mathrm{n} / \mathrm{a}$ & $\begin{array}{l}75.7 \% \text { BCR-free survival at } 36 \text { months } \\
\text { ( } 14.1 \% \text { underwent biopsy }-26 \% \text { were } \\
\text { positive) }\end{array}$ \\
\hline $\begin{array}{l}\text { Stabile et al. } \\
(2019)(16)\end{array}$ & $\begin{array}{l}\text { Prospective, } \\
\text { multicenter }\end{array}$ & HIFU & 1,032 & $80.3 \%$ GG2+ & $\begin{array}{l}\text { Baseline MRI } \\
\text { in all patients }\end{array}$ & $\begin{array}{l}81 \% \text { freedom from radical treatment at } \\
96 \text { mos ( } 41.1 \% \text { underwent biopsy, } 24.7 \% \\
\text { biopsy failure) }\end{array}$ \\
\hline $\begin{array}{l}\text { Tracey et al. } \\
(2020)(19)\end{array}$ & $\begin{array}{l}\text { Prospective, } \\
\text { single center }\end{array}$ & PDT & 51 & GG2 only & $\begin{array}{l}\text { MR-visible } \\
\text { lesions only }\end{array}$ & $\begin{array}{l}82 \% \text { absence of GG2 disease at 3-month } \\
\text { biopsy }\end{array}$ \\
\hline $\begin{array}{l}\text { Murray et al. } \\
(2016)(20)\end{array}$ & $\begin{array}{l}\text { Prospective, } \\
\text { single center }\end{array}$ & IRE & 25 & $28 \%$ GG2+ & $\begin{array}{l}\text { MR-visible I } \\
\text { esions only }\end{array}$ & $\begin{array}{l}84 \% \text { negative } 6-\text { month biopsy in ablation } \\
\text { zone; } 88 \% \text { freedom from radical treatment }\end{array}$ \\
\hline $\begin{array}{l}\text { Ting et al. } \\
(2016)(21)\end{array}$ & $\begin{array}{l}\text { Prospective, } \\
\text { single center }\end{array}$ & IRE & 25 & $92 \%$ GG2+ & $\begin{array}{l}\text { MR-visible } \\
\text { lesions only }\end{array}$ & $\begin{array}{l}\text { No in-field recurrences on mpMRI or biopsy; } \\
\text { significant cancer on biopsy in } 24 \% \text { at } \\
8 \text { months }\end{array}$ \\
\hline
\end{tabular}

MRI, magnetic resonance imaging; BCR, biochemical recurrence; HIFU, high-intensity focused ultrasound; PDT, photodynamic therapy; IRE, irreversible electroporation; FLA, focal laser ablation; VTP, vascular-targeted photodynamic therapy; AS, active surveillance; mpMRI, multi-parametric magnetic resonance imaging; RARP, robot-assisted radical prostatectomy.

Outcomes for HIFU from prospective trials are overall favorable. Albisinni et al. analyzed 7 HIFU studies including a total of 366 patients who underwent focal or hemiablation of unilateral prostate cancer, with a median followup of 2.2 years. They identified a negative biopsy rate at 1 year of $77 \%$ and a freedom from salvage treatment of $92 \%$. They also reported on promising functional outcomes data, including pad-free continence at 12 months in $96 \%$ of men (30). The largest prospectively treated cohort published to date was a multicenter study from Guillaumier et al. including 625 men, $72 \%$ of whom harbored Gleason
Grade Group 2 or greater disease. At a median follow-up of 56 months, they reported a freedom from radical or systemic therapy of $88 \%$, with a $98 \%$ metastasis-free survival and $100 \%$ cancer-specific survival. However, of this study group only 222 patients $(35.5 \%)$ underwent post-HIFU biopsy (15). It has been noted that posttreatment mpMRI has a sensitivity as low as $25 \%$ for detecting clinically significant prostate cancer, and thus any follow up protocol for HIFU patients would ideally involve incorporation of systematic biopsy (31).

Rischman et al. reported on a multicenter prospective 
study of 111 patients, of whom $26 \%$ were classified as Gleason Grade Group 2. At 12 months post-HIFU, 96 (95\%) and 94 (93\%) had no clinically significant cancer (Gleason Grade Group 2 or higher) in the treated and contralateral lobes, respectively. Absence of any cancer in the treated lobe was seen in $86 \%$ of patients (95\% CI: $79-93 \%$; 87/101), while absence of any cancer in the whole gland was seen in $67 \%$ (95\% CI: $58-77 \% ; 68 / 101)$. The radical treatment-free survival rate at 2 years was $89 \%$ (17).

Finally, Ehdaie et al. reported on their experience in a multicenter prospective phase IIb trial of MR-guided HIFU in 101 men with intermediate (Grade Group 2 and 3) risk prostate cancer. They found that $96 \%$ of men had no evidence of GG2+ disease on per-protocol 6- and 24-month surveillance MR-targeted and systematic biopsies, while $78 \%$ of patients had no evidence of GG2+ anywhere in the gland. No serious adverse events were noted, and sexual function was preserved in over $75 \%$ of men.

Transurethral ultrasound ablation (TULSA) has emerged as an alternative for HIFU, similarly utilizing functional MRI techniques to ablation prostate tissue. It has demonstrated efficacy in prospective trials evaluating wholegland treatment, and potential utilization in lesion-targeted ablation is being explored (32). Unlike HIFU, the TULSA platform uses a continuous sweeping ultrasound beam that is delivered from the prostatic urethra, with energy delivery tailored during treatment based on an anatomical temperature map using MR thermometry. Favorable outcomes have been reported, but further validation of TULSA is needed in the form of clinical trials.

\section{Photodynamic therapy (PDT)}

PDT utilizes a photochemical reaction triggered by a photosensitizing substance activated through exposure to a laser light source at an appropriate wavelength. Initially described in 1903 for the treatment of skin cancer, several agents have been tested and used as PDT in the ablation of different types of cancer.

Padeliporfin $\left(\right.$ Tookad $\left.^{\circledR}\right)$ is the most robustly studied of the available photosensitizing agents, derived from chlorophyll with sensitivity to laser light at wavelengths between $750 \mathrm{~nm}$ and $755 \mathrm{~nm}$. In clinical practice, laser fibers are inserted through a transperineal template under TRUS guidance. Immediately following drug administration, fibers are illuminated for 10 minutes in order to activate the padeliporfin. After intravenous administration, padeliporfin has minimal extravascular distribution, remaining in the bloodstream in high concentrations. Padeliporfin activation leads to a cascade of chemical reactions restricted to the vascular compartment that culminate in the release of high doses of free oxygen radicals (superoxide and hydroxyl radicals), responsible for endothelial damage and occlusion of tumor vascularization (33-36).

Although padeliporfin clears rapidly from the vasculature, residual uptake in the skin may affect photosensitivity, which has been a challenge for treatment (37). However when Weersink et al. assessed the cutaneous phototoxicity of padeliporfin in patients as part of a phase I trial of vasculartargeted photodynamic therapy (VTP) for recurrent prostate cancer, no cutaneous phototoxic effects were observed after treatment, suggesting that photosensitivity after padeliporfin-mediated VTP is negligible three hours after the procedure (38).

Azzouzi et al. performed a pooled analysis of data from one phase I/II and two-phase II clinical trials involving 117 men with localized Gleason Grade Group 1 or 2 prostate cancer treated with padeliporfin VTP. Patients received a 10-minute intravenous infusion of a single dose of $4 \mathrm{mg} / \mathrm{kg}$ padeliporfin, activated by a $753-\mathrm{nm}$ light at $200 \mathrm{~J} / \mathrm{cm}$. Hemi-ablation was performed on unilateral disease, while conservative subtotal ablation techniques were used in the bilateral cases. All studies aimed to evaluate outcomes at 6 months using the same drug and light parameters, with the primary endpoint being negative biopsy rates in the treated lobe. Treatment response was assessed by biopsy at 6 months, serum PSA measurement at 1, 3, and 6 months, and MRI at 1 week, and 3 and 6 months after the procedure (39). The 6-month negative biopsy rate was $68.4 \%$, and necrosis was observed by MRI after 1 week in $76.5 \%$. Adverse events occurred in $82.9 \%$ of patients, and were mostly mild or moderate including dysuria, urinary retention, erectile dysfunction, and voiding urgency. Six months after the procedure, there was a slight improvement in urinary function and only deterioration in sexual function $(40,41)$.

In 2017, Azzouzi et al. published the first and only prospective randomized phase III study comparing VTP to active surveillance in patients with low-risk prostate cancer. The 413 patients were randomly assigned to VTP (padeliporfin; $\mathrm{n}=206$ ) or active surveillance $(\mathrm{n}=207)$. After a median follow-up of 2 years, patients undergoing focal therapy (VTP) had a lower rate of disease progression [28\% vs. $58 \%$, adjusted hazard ratio (HR): $0.34,95 \%$ CI, 0.24-0.46; $\mathrm{P}<0.0001]$, higher rate of negative biopsies (49\% vs. $14 \%$, adjusted risk ratio: 3.67, 95\% CI, 2.53-5.33; $\mathrm{P}<0.0001)$ and less need for radical treatment, whether 
radiotherapy or surgery ( $6 \%$ vs. $29 \%, \mathrm{P}<0.0001)$. Analyses of International Index of Erectile Function (IIEF-15) and International Prostate Symptom Score (IPSS) questionnaires showed a deterioration of erectile and voiding functions in the first 6 months, but after 2 years of follow-up, there was no statistically significant difference in functional outcomes compared to the active surveillance group (18). This study led to the approval of VTP for the treatment of low risk localized prostate cancer in Europe.

More recently, preliminary results of an ongoing prospective phase II study using VTP treatment in patients with favorable (Gleason Grade Group 2) intermediate-risk prostate cancer were released in April 2020 from Tracey et al. Fifty-one patients were recruited for this study, which had an average follow-up of 8 months. At biopsy 3 months after treatment, $82 \%$ of the patients had an absence of Gleason Grade Group 2 disease. Twenty-two percent underwent retreatment with hemi-ablation. Of 16 patients completing one-year follow-up after VTP, 15 (94\%) did not present any Gleason pattern 4 or 5 in the biopsy findings. After 3 months, the average decline in the IIEF-5 score was 1 point and in the IPSS there was an average increase of 1 point, both compared with the data collected before treatment. There was no case of urinary incontinence described and the rate of grade 3 complications was $12 \%$ (six patients), all related to pelvic pain and completely resolved after 3 weeks (19).

\section{Irreversible electroporation (IRE)}

IRE is a tumor ablation technique using nonthermal highvoltage low-energy electrical pulses between electrodes to create permanent pores in the cell membrane; this leads to a disruption in cellular homeostasis that triggers cell death $(42,43)$. Currently NanoKnife ${ }^{\circledR}$ (AngioDynamics, Queensbury, NY, USA) is the only FDA-cleared IRE device. When performing IRE, up to 6 electrodes are placed in the margins of the target area through the perineum using a brachytherapy grid under ultrasound or MRI guidance. As with most focal ablation techniques, general anesthesia is required to prevent the patient from moving and inadvertently causing electrode displacement. Pulse delivery is calculated using proprietary software that accounts for the active electrode tip length and the distances between the electrodes, yielding an optimum electrical field ranging between 20 and 40 amperes (22).

In an early pilot study of partial gland ablation using
IRE in 25 patients from Murray et al., $84 \%$ of patients had negative 6-month biopsies in the ablation zone, with only one patient reporting new ED, and $94 \%$ of men reported normal urinary function at 12 months (20). In that study, only $12 \%$ of men went on to radical surgical management of their prostate cancer.

In their single-center study with low- to intermediaterisk patients, Ting et al. performed focal IRE in 25 patients. Post-treatment mpMRI and prostate biopsy were performed after 6 and 7 months, respectively. Within the treatment field, there were no suspicious findings on $\operatorname{mpMRI}(n=24)$ and no recurrence on biopsy $(n=21)$ in any patients. Adjacent to the treatment zone, mpMRI detected suspicious findings in five patients $(21 \%)$, of which four were significant on biopsy. Outside the treatment field, two patients $(8 \%)$ had suspicious findings on MRI and one patient $(5 \%)$ had a significant finding on biopsy. Only one grade $3+$ adverse event was reported, and there was no significant change from baseline in urinary, sexual, and bowel function (21). van den Bos et al. assessed 63 patients with high-volume Gleason Grade Group 1 or 2 localized prostate cancer who were treated with IRE. Infield recurrence rate was $16 \%$, with $24 \%$ of patients found to have persistent cancer anywhere within the prostate (22).

Scheltema et al. conducted a matched-pair analysis, comparing early oncologic outcomes and effects on quality of life, between IRE treatment and robot-assisted radical prostatectomy (RARP) in patients with high-volume Gleason Grade Group 1 and 2 localized prostate cancers. Fifty IRE patients were matched to 50 RARP patients by propensity score. Oncologic failure was defined as biochemical recurrence after RARP or positive follow-up biopsies after IRE. Posttreatment 12-month biopsy showed significant cancer in $29.5 \%$ of the IRE-treated patients, while none of the RARP patients experienced biochemical recurrence within the first 12 months of follow-up. Early surgical complications for RARP and IRE included 14 and 18 low-grade (Clavien-Dindo 1 or 2) complications, respectively. IRE was superior to RARP in preserving padfree continence $(\mathrm{P}=0.01)$ as well as erectile function $(\mathrm{P}=0.05)$ within the first 12 months, though analysis of Expanded Prostate Cancer Index Composite (EPIC) questionnaires showed no significant difference between the groups (23). The favorable side-effect profile across IRE studies and suggests overall safety of this modality, though additional prospective studies are indicated in intermediate risk disease given relatively high local recurrence rates. 


\section{Focal laser ablation (FLA)}

FLA of prostate tissue, also known as laser interstitial thermotherapy, utilizes laser fibers inserted into the prostate gland via a percutaneous perineal or transrectal approach. These high-energy laser fibers emit energy at wavelengths between 800 and $1,100 \mathrm{~nm}$, leading to a tissue coagulation effect through direct heating of the tissue $(28,44)$.

The largest published study of men with low- to intermediate-risk prostate cancer undergoing FLA from Walser $e t a l$. found no change in sexual or urinary function scores one year after treatment. Median follow-up period was 34 months. At 6 and 12 months, patients had clinical and MR imaging with biopsy of suspicious areas. Of the 120 men on the study, a reported $83 \%$ needed no retreatment at one year, suggesting potential early oncologic efficacy (24). A significant decrease in PSA was noted at 12 and 24 months $(\mathrm{P}<0.001)$. A number of small phase II prospective studies have evaluated both oncologic efficacy and quality-of-life outcomes following FLA with in-bore technique (45-47). However, the use of MRI-ultrasound fusion technology with FLA has shown comparable results, while increasing the convenience and availability of this technology (48).

\section{Focal therapy as salvage treatment}

Local recurrence of prostate cancer following definitive radiation therapy presents a challenging clinical conundrum for urologists. Despite surgical advances, salvage radical prostatectomy is associated with significant perioperative morbidity, as well as high rates of urinary incontinence and impotence (49). Whole-gland salvage cryotherapy and whole-gland salvage HIFU are plagued by similarly poor side effect profiles, with erectile dysfunction in up to $100 \%$ of cases. Severe genitourinary and gastrointestinal complications requiring operative intervention have been reported in up to $30 \%$ of patients undergoing wholegland ablation (50). This has led researchers to explore utilization of focal ablation to attempt to achieve local control in men who experience disease recurrence following radiation. There are no currently published prospective studies evaluating focal therapy in the salvage setting, but retrospective case studies provide encouraging rationale for this approach (Table 2).

An early study of VTP by Trachtenberg et al. assessed the outcomes of VTP treatment in 24 patients with recurrent prostate cancer after external beam radiation therapy (EBRT) (60). Complete pathologic response at 6-month biopsy required at least a $23 \mathrm{~J} / \mathrm{cm}^{2}$ dose in $90 \%$ of the prostate and was seen in 8 of 13 patients who received treatment under those parameters. MRI changes were observed in all patients, and $>60 \%$ image response was associated with a complete pathologic response. Sexual, urinary, and bowel function returned to the baseline level 6 months after VTP. Notably, rectal wall devascularization was observed in ten patients, and recto-urethral fistula was diagnosed in 2. Though the oncologic outcomes are encouraging, the potential for rectal toxicity suggests that clinicians should proceed with caution when utilizing VTP for radio-recurrent disease and council patients appropriately (61).

IRE has been reported as a potentially effective options for focal salvage treatment, with limited case reports of successful eradication of cancer following failure of brachytherapy and focal cryotherapy (62). In a retrospective comparative study, de Castro Abreu et al. evaluated 50 men treated with either focal or whole-gland salvage cryotherapy for radio-recurrent prostate cancer. They found similar rates of biochemical recurrence free survival in both groups, while the focally treated patients had lower rates of incontinence and erectile dysfunction (54). Similarly, Tan et al. found in their retrospective comparative cohort study of 385 men in the COLD registry that oncologic outcomes were comparable between focal and whole-gland ablation. However, they did not find significant difference in the rates of rectal fistula, urinary incontinence, or erectile dysfunction between the groups (63). Other published series of focal salvage HIFU have demonstrated failure rates of over $50 \%$, notably worse than whole-gland salvage therapies (57). With conflicting data in the published literature, there is a clear need for high-quality prospective trials evaluating the efficacy of focal salvage therapies they can be considered recommended options.

\section{Conclusions}

The role of focal therapy in the urologist's armamentarium of treatments for clinically localized prostate cancer is continuously evolving, but existing trial data has shown these technologies to be generally safe with favorable side effect profiles. Currently there is no single ablative technology that has demonstrably superior oncologic efficacy, and all must be considered experimental until more robust long-term evidence emerges directly comparing focal therapy to standard of care radical treatment. 
Table 2 Retrospective studies evaluating efficacy and side effects of focal salvage therapies for radio-recurrent prostate cancer

\begin{tabular}{|c|c|c|c|c|c|c|}
\hline Study & $\begin{array}{l}\text { Ablation } \\
\text { modality }\end{array}$ & Patients & Erectile dysfunction & $\begin{array}{c}\text { Urinary } \\
\text { incontinence }\end{array}$ & Complications & Key oncologic outcome \\
\hline $\begin{array}{l}\text { Bomers et al. } \\
(2020)(51)\end{array}$ & Cryotherapy & 62 & $\begin{array}{l}\text { Post-op potency } \\
\text { preserved in } 41 \% \\
\text { (15/37 pts) }\end{array}$ & $3.2 \%$ & $\begin{array}{l}\text { Clavien } 3+\text { in } 2 \text { pts (3.2\%); } \\
\text { rectovesical fistula in } 1 \mathrm{pt}\end{array}$ & $\begin{array}{l}83 \% \text { disease-free } \\
\text { survival at } 6 \text { months }\end{array}$ \\
\hline $\begin{array}{l}\text { Overduin et al. } \\
(2017)(52)\end{array}$ & Cryotherapy & 47 & Not assessed & Not assessed & Not reported & $\begin{array}{l}\text { "Local control" in 24/47 } \\
\text { pts }(51 \%)\end{array}$ \\
\hline $\begin{array}{l}\text { de Castro Abreu } \\
\text { et al. (2013) (54) }\end{array}$ & Cryotherapy & 25 & $\begin{array}{l}\text { Post-op potency } \\
\text { preserved in } 2 / 7 \text { pts } \\
(29 \%)\end{array}$ & $0 \%$ & None & $\begin{array}{l}\text { Biochemical failure in } \\
32 \%(8 / 25)\end{array}$ \\
\hline $\begin{array}{l}\text { Eisenberg and } \\
\text { Shinohara (2008) (56) }\end{array}$ & Cryotherapy & 19 & Not assessed & $7 \%(1 / 15 \mathrm{pts})$ & $\begin{array}{l}\text { Urethral stricture }(1 \mathrm{pt}) \text {, } \\
\text { urethral ulcer (1 pt) }\end{array}$ & $\begin{array}{l}\text { Biochemical failure in } \\
50 \% \text { at } 3 \text { years }\end{array}$ \\
\hline $\begin{array}{l}\text { Kanthabalan } \\
\text { et al. (2017) (57) }\end{array}$ & HIFU & 150 & $\begin{array}{l}\text { Post-op potency } \\
\text { preserved in } 7 / 12 \text { pts } \\
(58.3 \%)\end{array}$ & $\begin{array}{c}\text { Continence } \\
\text { preserved in } \\
87.5 \% \text { at } 2 \text { years }\end{array}$ & $\begin{array}{l}\text { BNC in } 8 \%, \text { rectourethral } \\
\text { fistula in } 2 \%\end{array}$ & $\begin{array}{l}\text { Biochemical failure in } \\
51 \% \text { at } 3 \text { years }\end{array}$ \\
\hline $\begin{array}{l}\text { Baco et al. } \\
(2014)(58)\end{array}$ & HIFU & 48 & $\begin{array}{l}\text { Mean decline in } \\
\text { IIEF- } 5 \text { of } 4.2 \text { points }\end{array}$ & $25 \%$ & Osteitis pubis in 2 patients & $\begin{array}{l}\text { Progression-free } \\
\text { survival in } 52 \% \text { at } \\
2 \text { years }\end{array}$ \\
\hline $\begin{array}{l}\text { Ahmed et al. } \\
\text { (2012) (59) }\end{array}$ & HIFU & 39 & $\begin{array}{l}\text { Mean decline in } \\
\text { IIEF- } 5 \text { of } 5 \text { points }\end{array}$ & $36 \%$ & $\begin{array}{l}\text { Gr } 3+\text { in } 26 \% \text {, rectourethral } \\
\text { fistula in } 3.6 \%\end{array}$ & $\begin{array}{l}\text { Biochemical failure in } \\
58 \% \text { at } 3 \text { years }\end{array}$ \\
\hline
\end{tabular}

HIFU, high-intensity focused ultrasound; BOO, bladder outlet obstruction; IIEF, International Index of Erectile Function.

Regardless of the ablation modality utilized, it seems likely that ongoing improvements in prostate imaging technology and refinement of patient selection criteria that will help to clarify the role that focal therapy will play in the future.

\section{Acknowledgments}

Funding: This work was supported by the Sidney Kimmel Center for Prostate and Urologic Cancers and a National Institutes of Health/National Cancer Institute Cancer Center Support Grant [P30CA008748].

\section{Footnote}

Provenance and Peer Review: This article was commissioned by the Guest Editors (Badrinath R. Konety, Daniel W. Lin) for the series "Current and Future Topics on Prostate
Cancer" published in Translational Andrology and Urology. The article has undergone external peer review.

Reporting Checklist: The authors have completed the Narrative Review reporting checklist. Available at https:// dx.doi.org/10.21037/tau-20-1212

Conflicts of Interest: All authors have completed the ICMJE uniform disclosure form (available at https://dx.doi. org/10.21037/tau-20-1212). The series "Current and Future Topics on Prostate Cancer" was commissioned by the editorial office without any funding or sponsorship. The authors have no other conflicts of interest to declare.

Ethical Statement: The authors are accountable for all aspects of the work in ensuring that questions related to the accuracy or integrity of any part of the work are 
appropriately investigated and resolved.

Open Access Statement: This is an Open Access article distributed in accordance with the Creative Commons Attribution-NonCommercial-NoDerivs 4.0 International License (CC BY-NC-ND 4.0), which permits the noncommercial replication and distribution of the article with the strict proviso that no changes or edits are made and the original work is properly cited (including links to both the formal publication through the relevant DOI and the license). See: https://creativecommons.org/licenses/by-nc-nd/4.0/.

\section{References}

1. Howlader N, Noone AM, Krapcho M, et al. SEER Cancer Statistics Review, 1975-2017. Bethesda: National Cancer Institute. 2020. Available online: https://seer.cancer.gov/ csr/1975_2017/

2. Sanda MG, Cadeddu JA, Kirkby E, et al. Clinically Localized Prostate Cancer: AUA/ASTRO/SUO Guideline. Part II: Recommended Approaches and Details of Specific Care Options. J Urol 2018;199:990-7.

3. Mohler JL, Antonarakis ES, Armstrong AJ, et al. Prostate Cancer, Version 2.2019, NCCN Clinical Practice Guidelines in Oncology. J Natl Compr Canc Netw 2019;17:479-505.

4. Connor MJ, Gorin MA, Ahmed HU, et al. Focal therapy for localized prostate cancer in the era of routine multi-parametric MRI. Prostate Cancer Prostatic Dis 2020;23:232-43.

5. Mouraviev V, Villers A, Bostwick DG, et al. Understanding the pathological features of focality, grade and tumour volume of early-stage prostate cancer as a foundation for parenchyma-sparing prostate cancer therapies: active surveillance and focal targeted therapy. BJU Int 2011;108:1074-85.

6. Perera M, Krishnananthan N, Lindner U, et al. An update on focal therapy for prostate cancer. Nat Rev Urol 2016;13:641-53.

7. Ahdoot M, Wilbur AR, Reese SE, et al. MRI-Targeted, Systematic, and Combined Biopsy for Prostate Cancer Diagnosis. N Engl J Med 2020;382:917-28.

8. Hamdy FC, Donovan JL, Lane JA, et al. 10-Year Outcomes after Monitoring, Surgery, or Radiotherapy for Localized Prostate Cancer. N Engl J Med 2016;375:1415-24.

9. Klotz L, Vesprini D, Sethukavalan P, et al. Long-term follow-up of a large active surveillance cohort of patients with prostate cancer. J Clin Oncol 2015;33:272-7.

10. Donaldson IA, Alonzi R, Barratt D, et al. Focal therapy: patients, interventions, and outcomes--a report from a consensus meeting. Eur Urol 2015;67:771-7.

11. Horwitz EM, Thames HD, Kuban DA, et al. Definitions of biochemical failure that best predict clinical failure in patients with prostate cancer treated with external beam radiation alone: a multi-institutional pooled analysis. J Urol 2005;173:797-802.

12. van der Poel HG, van den Bergh RCN, et al. Focal Therapy in Primary Localised Prostate Cancer: The European Association of Urology Position in 2018. Eur Urol 2018;74:84-91.

13. Shah TT, Peters M, Eldred-Evans D, et al. EarlyMedium-Term Outcomes of Primary Focal Cryotherapy to Treat Nonmetastatic Clinically Significant Prostate Cancer from a Prospective Multicentre Registry. Eur Urol 2019;76:98-105.

14. Ward JF, Jones JS. Focal cryotherapy for localized prostate cancer: a report from the national Cryo On-Line Database (COLD) Registry. BJU Int 2012;109:1648-54.

15. Guillaumier S, Peters M, Arya M, et al. A Multicentre Study of 5-year Outcomes Following Focal Therapy in Treating Clinically Significant Nonmetastatic Prostate Cancer. Eur Urol 2018;74:422-9.

16. Stabile A, Orczyk C, Hosking-Jervis F, et al. Medium-term oncological outcomes in a large cohort of men treated with either focal or hemi-ablation using high-intensity focused ultrasonography for primary localized prostate cancer. BJU Int 2019;124:431-40.

17. Rischmann P, Gelet A, Riche B, et al. Focal High Intensity Focused Ultrasound of Unilateral Localized Prostate Cancer: A Prospective Multicentric Hemiablation Study of 111 Patients. Eur Urol 2017;71:267-73.

18. Azzouzi AR, Vincendeau S, Barret E, et al. Padeliporfin vascular-targeted photodynamic therapy versus active surveillance in men with low-risk prostate cancer (CLIN1001 PCM301): an open-label, phase 3, randomised controlled trial. Lancet Oncol 2017;18:181-91.

19. Tracey A, Nogueira L, Alvim R, et al. LBA02-04 INTERIM RESULTS: A PHASE 2B TRIAL OF PADELIPORFIN (WST11) VASCULAR-TARGETED PHOTODYNAMIC THERAPY AS PARTIAL-GLAND ABLATION FOR MEN WITH INTERMEDIATERISK PROSTATE CANCER. J Urol 2020;203:e1116.

20. Murray KS, Ehdaie B, Musser J, et al. Pilot Study to Assess Safety and Clinical Outcomes of Irreversible Electroporation for Partial Gland Ablation in Men with 
Prostate Cancer. J Urol 2016;196:883-90.

21. Ting F, Tran M, Böhm M, et al. Focal irreversible electroporation for prostate cancer: functional outcomes and short-term oncological control. Prostate Cancer Prostatic Dis 2016;19:46-52.

22. van den Bos $W$, Scheltema MJ, Siriwardana AR, et al. Focal irreversible electroporation as primary treatment for localized prostate cancer. BJU Int 2018;121:716-24.

23. Scheltema MJ, Chang JI, Böhm M, et al. Pair-matched patient-reported quality of life and early oncological control following focal irreversible electroporation versus robot-assisted radical prostatectomy. World J Urol 2018;36:1383-9.

24. Walser E, Nance A, Ynalvez L, et al. Focal Laser Ablation of Prostate Cancer: Results in 120 Patients with Lowto Intermediate-Risk Disease. J Vasc Interv Radiol 2019;30:401-409.e2.

25. Onik G, Narayan P, Vaughan D, et al. Focal "nervesparing" cryosurgery for treatment of primary prostate cancer: a new approach to preserving potency. Urology 2002;60:109-14.

26. Tay KJ, Polascik TJ, Elshafei A, et al. Propensity ScoreMatched Comparison of Partial to Whole-Gland Cryotherapy for Intermediate-Risk Prostate Cancer: An Analysis of the Cryo On-Line Data Registry Data. J Endourol 2017;31:564-71.

27. Valerio M, Cerantola Y, Eggener SE, et al. New and Established Technology in Focal Ablation of the Prostate: A Systematic Review. Eur Urol 2017;71:17-34.

28. Ganzer R, Arthanareeswaran VKA, Ahmed HU, et al. Which technology to select for primary focal treatment of prostate cancer?-European Section of Urotechnology (ESUT) position statement. Prostate Cancer Prostatic Dis 2018;21:175-86.

29. Napoli A, Anzidei M, De Nunzio C, et al. Real-time magnetic resonance-guided high-intensity focused ultrasound focal therapy for localised prostate cancer: preliminary experience. Eur Urol 2013;63:395-8.

30. Albisinni S, Mélot C, Aoun F, et al. Focal Treatment for Unilateral Prostate Cancer Using High-Intensity Focal Ultrasound: A Comprehensive Study of Pooled Data. J Endourol 2018;32:797-804.

31. Ganzer R, Hadaschik B, Pahernik S, et al. Prospective Multicenter Phase II Study on Focal Therapy (Hemiablation) of the Prostate with High Intensity Focused Ultrasound. J Urol 2018;199:983-9.

32. Klotz L, Pavlovich CP, Chin J, et al. Magnetic Resonance Imaging-Guided Transurethral Ultrasound Ablation of
Prostate Cancer. J Urol 2021;205:769-79.

33. Gheewala T, Skwor T, Munirathinam G. Photosensitizers in prostate cancer therapy. Oncotarget 2017;8:30524-38.

34. Neuschmelting V, Kim K, Malekzadeh-Najafabadi J, et al. WST11 Vascular Targeted Photodynamic Therapy Effect Monitoring by Multispectral Optoacoustic Tomography (MSOT) in Mice. Theranostics 2018;8:723-34.

35. Moore CM, Azzouzi AR, Barret E, et al. Determination of optimal drug dose and light dose index to achieve minimally invasive focal ablation of localised prostate cancer using WST11-vascular-targeted photodynamic (VTP) therapy. BJU Int 2015;116:888-96.

36. Azzouzi AR, Emberton M; PCM301 study investigators. Padeliporfin vascular-targeted photodynamic therapy versus active surveillance in men with low-risk prostate cancer - Authors' reply. Lancet Oncol 2017;18:e188.

37. Weersink R A, Wilson B C, Patterson M S. Determination of the peak absorption wavelength and disaggregation kinetics of TOOKAD in vivo using dynamic, spatially resolved diffuse reflectance spectroscopy in a rabbit model. Optical Biopsy IV. International Society for Optics and Photonics 2002;4613:135-42.

38. Weersink RA, Forbes J, Bisland S, et al. Assessment of cutaneous photosensitivity of TOOKAD (WST09) in preclinical animal models and in patients. Photochem Photobiol 2005;81:106-13.

39. Azzouzi AR, Barret E, Bennet J, et al. TOOKAD® Soluble focal therapy: pooled analysis of three phase II studies assessing the minimally invasive ablation of localized prostate cancer. World J Urol 2015;33:945-53.

40. Steba Biotech SA. Safety and tolerability study using WST11 in patients with localized prostate cancer. ClinicalTrials.gov. Bethesda: National Library of Medicine (US).

41. Azzouzi AR, Lebdai S, Benzaghou F, et al. Vasculartargeted photodynamic therapy with TOOKAD® Soluble in localized prostate cancer: standardization of the procedure. World J Urol 2015;33:937-44.

42. Hübner N, Shariat SF, Remzi M. Focal therapy of prostate cancer. Curr Opin Urol 2018;28:550-4.

43. Lee EW, Thai S, Kee ST. Irreversible electroporation: a novel image-guided cancer therapy. Gut Liver 2010;4 Suppl 1:S99-S104.

44. van Luijtelaar A, Greenwood BM, Ahmed HU, et al. Focal laser ablation as clinical treatment of prostate cancer: report from a Delphi consensus project. World J Urol 2019;37:2147-53.

45. Eggener SE, Yousuf A, Watson S, et al. Phase II Evaluation 
of Magnetic Resonance Imaging Guided Focal Laser Ablation of Prostate Cancer. J Urol 2016;196:1670-5.

46. Chao B, Llukani E, Lepor H. Two-year Outcomes Following Focal Laser Ablation of Localized Prostate Cancer. Eur Urol Oncol 2018;1:129-33.

47. Al-Hakeem Y, Raz O, Gacs Z, et al. Magnetic resonance image-guided focal laser ablation in clinically localized prostate cancer: safety and efficacy. ANZ J Surg 2019;89:1610-4.

48. Natarajan S, Jones TA, Priester AM, et al. Focal Laser Ablation of Prostate Cancer: Feasibility of Magnetic Resonance Imaging-Ultrasound Fusion for Guidance. J Urol 2017;198:839-47.

49. Mohler JL, Halabi S, Ryan ST, et al. Management of recurrent prostate cancer after radiotherapy: long-term results from CALGB 9687 (Alliance), a prospective multiinstitutional salvage prostatectomy series. Prostate Cancer Prostatic Dis 2019;22:309-16.

50. van Son M, Peters M, Moerland M, et al. Focal Salvage Treatment of Radiorecurrent Prostate Cancer: A Narrative Review of Current Strategies and Future Perspectives. Cancers (Basel) 2018;10:480.

51. Bomers JGR, Overduin CG, Jenniskens SFM, et al. Focal Salvage MR Imaging-Guided Cryoablation for Localized Prostate Cancer Recurrence after Radiotherapy: 12-Month Follow-up. J Vasc Interv Radiol 2020;31:35-41.

52. Overduin CG, Jenniskens SFM, Sedelaar JPM, et al. Percutaneous MR-guided focal cryoablation for recurrent prostate cancer following radiation therapy: retrospective analysis of iceball margins and outcomes. Eur Radiol 2017;27:4828-36.

53. Li YH, Elshafei A, Agarwal G, et al. Salvage focal prostate cryoablation for locally recurrent prostate cancer after radiotherapy: initial results from the cryo on-line data registry. Prostate 2015;75:1-7.

54. de Castro Abreu AL, Bahn D, Leslie S, et al. Salvage focal and salvage total cryoablation for locally recurrent prostate cancer after primary radiation therapy. BJU Int 2013;112:298-307.

55. Wenske S, Quarrier S, Katz AE. Salvage cryosurgery

Cite this article as: Tracey AT, Nogueira LM, Alvim RG, Coleman JA, Murray KS. Focal therapy for primary and salvage prostate cancer treatment: a narrative review. Transl Androl Urol 2021;10(7):3144-3154. doi: 10.21037/tau-20-1212 of the prostate for failure after primary radiotherapy or cryosurgery: long-term clinical, functional, and oncologic outcomes in a large cohort at a tertiary referral centre. Eur Urol 2013;64:1-7.

56. Eisenberg ML, Shinohara K. Partial salvage cryoablation of the prostate for recurrent prostate cancer after radiotherapy failure. Urology 2008;72:1315-8.

57. Kanthabalan A, Peters M, Van Vulpen M, et al. Focal salvage high-intensity focused ultrasound in radiorecurrent prostate cancer. BJU Int 2017;120:246-56.

58. Baco E, Gelet A, Crouzet S, et al. Hemi salvage highintensity focused ultrasound (HIFU) in unilateral radiorecurrent prostate cancer: a prospective two-centre study. BJU Int 2014;114:532-40.

59. Ahmed HU, Cathcart P, McCartan N, et al. Focal salvage therapy for localized prostate cancer recurrence after external beam radiotherapy: a pilot study. Cancer 2012;118:4148-55.

60. Trachtenberg J, Bogaards A, Weersink RA, et al. Vascular targeted photodynamic therapy with palladiumbacteriopheophorbide photosensitizer for recurrent prostate cancer following definitive radiation therapy: assessment of safety and treatment response. J Urol 2007;178:1974-9; discussion 1979.

61. Trachtenberg J, Weersink RA, Davidson SR, et al. Vascular-targeted photodynamic therapy (padoporfin, WST09) for recurrent prostate cancer after failure of external beam radiotherapy: a study of escalating light doses. BJU Int 2008;102:556-62.

62. Murray KS, Akin O, Coleman JA. Irreversible Electroporation for Prostate Cancer as Salvage Treatment Following Prior Radiation and Cryotherapy. Rev Urol 2017;19:268-72.

63. Tan WP, ElShafei A, Aminsharifi A, et al. Salvage Focal Cryotherapy Offers Similar Short-term Oncologic Control and Improved Urinary Function Compared With Salvage Whole Gland Cryotherapy for Radiation-resistant or Recurrent Prostate Cancer. Clin Genitourin Cancer 2020;18:e260-5. 